\title{
The evaluation of gestation length range for different breeds of Polish dairy cattle
}

\author{
Zbigniew Sobek ${ }^{1}$, Anna Nienartowicz-Zdrojewska ${ }^{1}$, \\ Jolanta Różańska-Zawieja ${ }^{1}$, Idzi Siatkowski ${ }^{2}$ \\ ${ }^{1}$ Department of Genetics and Animal Breeding, Poznan University of Life Science, Wołyńska 33, \\ 60-637 Poznań, e-mail: anianzdr@gmail.com \\ ${ }^{2}$ Departament of Mathematical and Statistical Methods, Poznan University of Life Science, \\ Wojska Polskiego 28, 60-637 Poznań
}

\section{SUMMARY}

\begin{abstract}
For over 2.5 million dairy cows subject to assessment in Poland in 2005-2010, gestation length was analyzed. This trait follows a normal distribution, and it was found that the acceptable upper limit of gestation length for the Montbéliard and Simental breeds was 306 days, this being significantly different from other breeds. For the remaining dairy cattle breeds the value was 298 days. For cows with gestation length exceeding these limiting values, parentage control would be advisable.
\end{abstract}

Key words: dairy cattle, gestation length

\section{Introduction}

Gestation length in mammals is a physiological trait, characteristic of species or even of breed. Within the fixed limits there may be some individual variations within a breed, still considered to be standard. Establishing the range of these variations is economically important, as it may reduce the costs of parentage control of individuals born out of particularly long pregnancies. Gestation length is strongly influenced by a number of non-genetic factors, e.g. calving season, herd, lactation number, sex of the calf or parturition type (Petrović et al., 2010; Norman et al., 2009). Physiological gestation length in dairy cows in Poland, according to the assessment instructions, is 263 to 297 days, or 263 to 300 days for Montbéliard and Simmental. When the acceptable gestation length 
is exceeded, parentage control is required. Lopez de Maturana et al. (2009), analyzing a population of over 90000 individuals, estimated the gestation length for Holstein-Frisian (H-F) cows to be from 261 to 291 days (with a mean of 277.6). Hansen et al. (2004), for 390,000 Holstein-Frisian heifers, recorded a mean of 278.5 days and a range of 256 to 300 days. Observation of this variability motivated a study of gestation length differences among cattle breeds, in order to establish physiological standards for the currently assessed dairy cattle population in Poland and to reduce the costs of parentage control.

\section{Materials and methods}

The study concerned all dairy cattle subject to breeding and production value assessment in Poland. The database comprised individuals of 5 dairy cattle breeds: Holstein-Friesian (HF) Black-White variety (HO) and HF Red-White variety (RW), Jersey (JE), Montbéliard (MO) and Simental (SM), along with 4 conservation breeds: Polish Red (RP), Polish Black-White (ZB), Polish RedWhite (ZR) and Whitebacked (BG). The SYMLEK national evaluation system provided a total of 2,588,982 records. The data relate to 2005-2010 calving records. Incomplete records, and records of stillbirths and gestations shorter than 254 days, were removed. The system permits the recording of pregnancies not longer than 297 days.

With this great number of records it is possible to assume, according to the central limit theorem, that the analyzed trait follows a normal distribution (Feller, 1971). As factors disturbing the genetic equilibrium, and, at the same time, the normality of trait distribution influence the breeding population, the concordance of the data with the normal distribution was analyzed for the material as a whole and for particular breeds. The Kolgomorov statistic was used in order to check the concordance with normal distribution for the gestation length trait, as the analyzed sample is very large with no restriction on information about the hypothetical distribution parameters (Xing et al., 2011). 
Table 1. Characteristics of mean gestation length in different dairy cattle breeds in Poland

\begin{tabular}{lcrrr}
\hline \multicolumn{1}{c}{ Breed } & Breed Code & \multicolumn{1}{c}{ No. } & \multicolumn{1}{c}{ Mean } & \multicolumn{1}{l}{ SD } \\
\hline Holstein-Friesian Black-White & HO & $1,769,065$ & 279.9 & 6.17 \\
Holstein-Friesian Red-White & RW & 55,431 & 279.0 & 6.40 \\
Jersey & JE & 3,911 & 280.3 & 5.64 \\
Montbéliard & MO & 18,405 & 286.6 & 6.78 \\
Simental & SM & 2,172 & 283.5 & 6.56 \\
Polish Red-White & ZR & 6,208 & 281.5 & 6.35 \\
Polish Red & RP & 5,396 & 283.3 & 5.90 \\
Polish Black-White & ZB & 3,508 & 280.5 & 6.51 \\
Whitebacked & BG & 324 & 281.1 & 6.33 \\
\hline Total & All & $1,864,420$ & 279.9 & 6.22 \\
\hline
\end{tabular}

The Kolmogorov statistic $D$ is defined as

$$
\mathrm{D}=\sup _{-\infty<\mathrm{x}<+\infty}\left|\mathrm{S}_{\mathrm{n}}(\mathrm{x})-\mathrm{F}(\mathrm{x})\right|
$$

where $S_{n}(x)$ denotes empirical distribution function, $F(x)$ normal distribution function.

On the basis of the estimated mean value $\mu$ and the standard deviation $\sigma$ for the whole of the material a theoretical graph was created for the density function $\mathrm{f}(\mathrm{x})$ (Fig. 1):

$$
f(x)=\frac{1}{\sigma \sqrt{2 \pi}} \exp \left[-\frac{(x-\mu)^{2}}{2 \sigma^{2}}\right]
$$

On the theoretical density function graph, areas were marked according to the "rule of $3 \sigma$ " to illustrate acceptable trait values.

For comparing differences in gestation length in the breeds, multifactor analysis of covariance was used, where the main fixed effects were breeds, herd-year-season, lactation number, number of calves and regression effect of calf birth weight, as well as the random effect of service sire. 


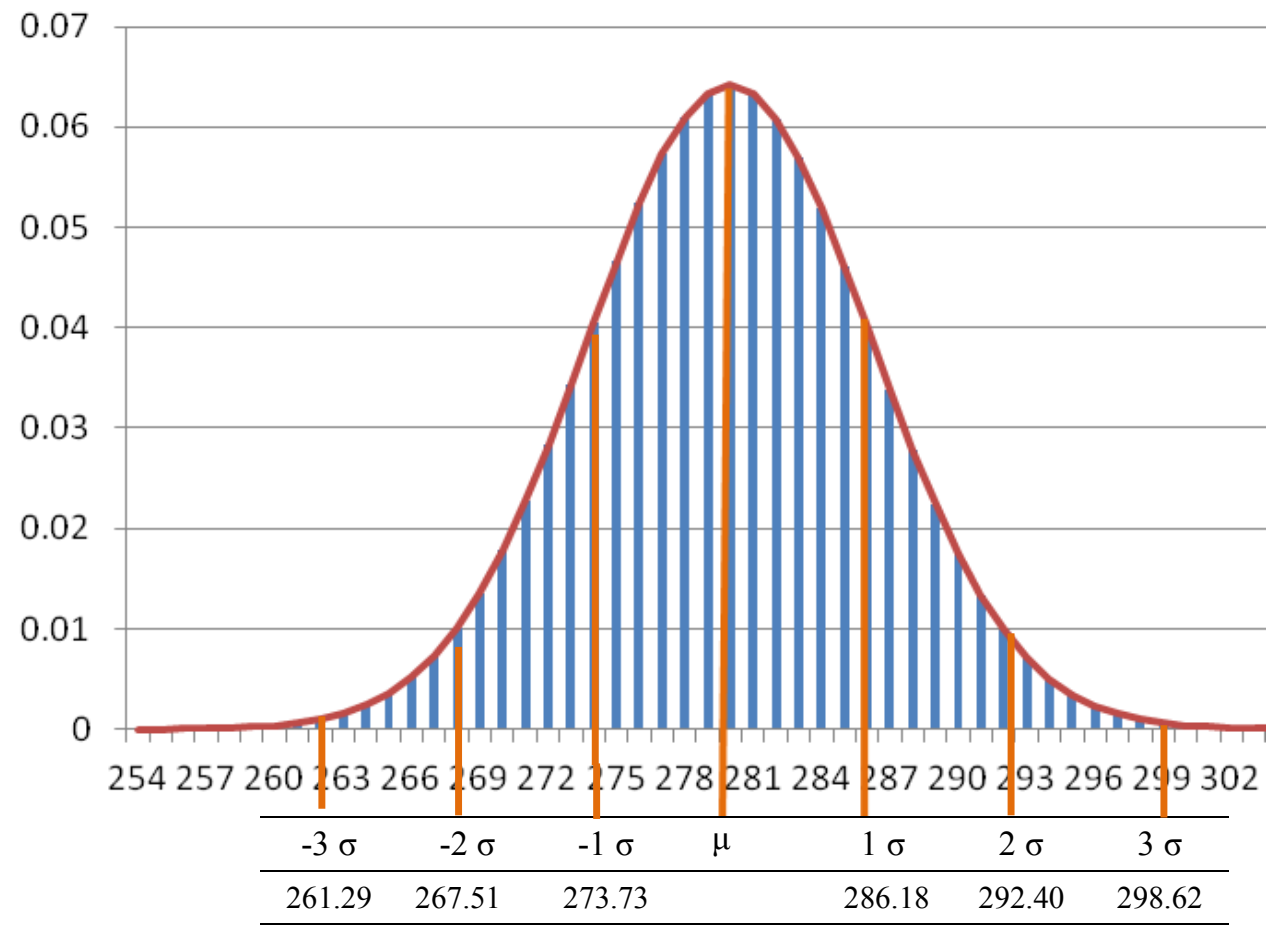

Figure 1. Density function graph $\mathrm{f}(\mathrm{x})$ for the whole set [with fixed $\mu=279.9$ and $\sigma=6.22]$

In this model gestation length is a normally distributed continuous random variable, and body weight is a covariable. Total regression was estimated to be 0.12839 , and the $t$-statistic (122.45) was significant for $p \leq 0.0001$. The variable homogeneity was confirmed by Bartlett's test.

All of the calculations were performed with the SAS (2010) statistical package, using the MEANS, UNIVARIATE and GLM procedures with the LSD test for the mixed model:

$$
\mathrm{Y}_{\mathrm{ijklmop}}=\mu+\mathrm{B}_{\mathrm{i}}+\mathrm{HYS}_{\mathrm{ij}}+\mathrm{S}_{\mathrm{ik}}+\mathrm{L}_{1}+\mathrm{P}_{\mathrm{m}}+\mathrm{G}_{\mathrm{n}}+\beta\left(\mathrm{x}_{\mathrm{o}}-\overline{\mathrm{x}}\right)+\mathrm{e}_{\mathrm{ijk} k m n o p},
$$

where $Y_{i j k l m o p}$ denotes gestation length in days, $\mu$ - total population mean, $B_{i}-$ breeds, $\mathrm{HYS}_{\mathrm{ij}}$ - fixed effect of herd-year-season of calving, $\mathrm{S}_{\mathrm{ik}}$ - random effect of service sire, $L_{1}$ - fixed effect of lactation number, $P_{m}-$ fixed effect of number of calves, $\mathrm{G}_{\mathrm{n}}$ - fixed effect of calf sex, $\beta\left(\mathrm{x}_{\mathrm{o}}-\overline{\mathrm{x}}\right)$ - fixed effect of regression on 
calf birth weight, $\mathrm{x}_{\mathrm{o}}-$ calf birth weight, $\overline{\mathrm{x}}-$ average calf birth weight, $\mathrm{e}_{\mathrm{ijklmnop}}-$ random residual.

\section{Results and discussion}

On the basis of the parameters obtained for the whole of the analyzed population of dairy cattle, a theoretical density function graph was created, showing that $99.3 \%( \pm 3 \sigma)$ of all the observations were contained within a range of 261.30 to 298.62 days.

Analysis of covariance showed differences in gestation length for all of the factors in the model. The differences were statistically significant for $\mathrm{p} \leq 0.0001$. For breeds only, the statistical significance of differences between breed pair means was estimated, using the LSD test $(\alpha \leq 0.01)$.

The upper limit of gestation length in the study of Olson et al. (2009) was also higher than the advised 297 days. For Holstein-Frisian cattle the maximum was 299 days.

There was significant differentiation among the analyzed 9 dairy cattle breeds in the average gestation length: from 279.9 days for HO to 286.6 days for SM.

The LSD test showed highly significant differences among the mean values for these breeds. There are sets of breeds within which there were no differences recorded: $\mathrm{HO}, \mathrm{RW}$, and JE (denoted as group A); $\mathrm{MO}$ and $\mathrm{RP}$ (B); BG and ZB (C); furthermore SM was denoted as $\mathrm{D}$, and ZR as E (Fig. 2). The objects denoted with the same capital letter were combined into groups and compared/tested with orthogonal contrasts, and between these groups significant differences were confirmed.

Similar differentiation among breeds was noted by Norman et al. (2009), who identified additional differentiation within a breed caused by calf sex, number of calves, the level of lactation, lactation length, etc. 


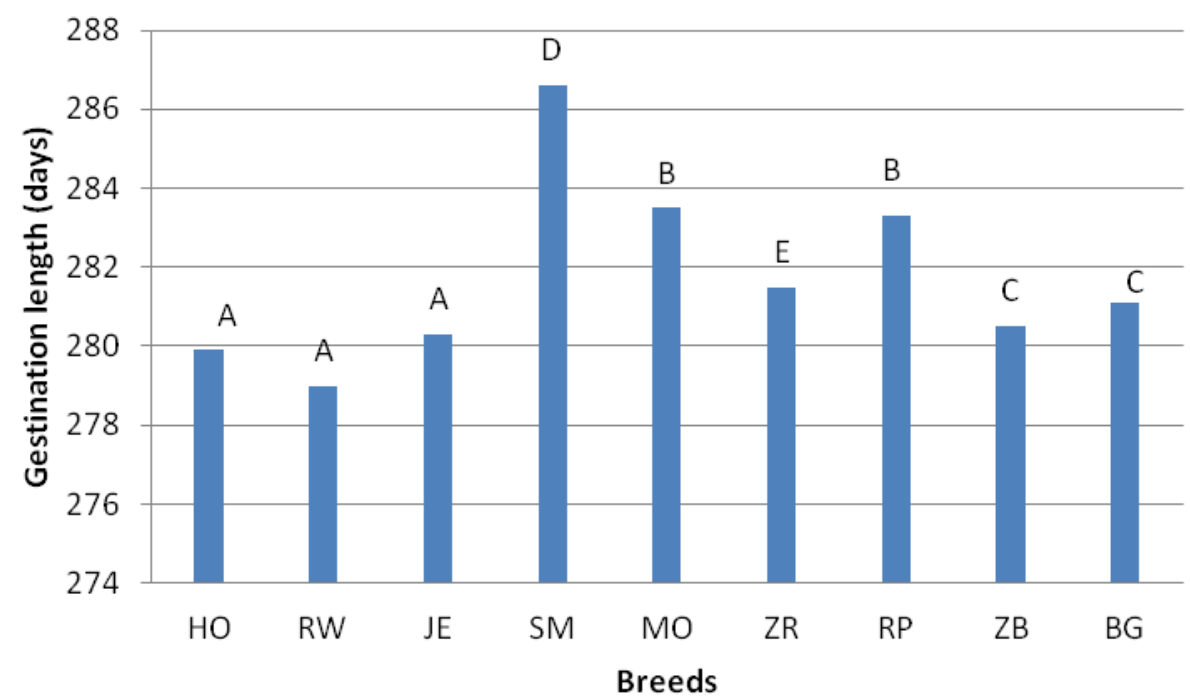

* where the difference among breeds marked with different capital letters A, B, .., E is highly statistically significant $(\alpha \leq 0.01)$.

Figure 2. Differences in mean gestation length in selected dairy cattle breeds

For particular breeds the analyzed trait was found to fit a normal distribution, using the Kolgomorov statistics, and this was also the case for the whole of the material (Fig. 3a) and for the groups presented in figures $3 \mathrm{~b}$ and $3 \mathrm{c}$.

The analysis of gestation length was performed for all available breeds, and, separately, for all except MO and SM. Breeds MO and SM were also analyzed separately, because they differ in production type, which is expected to influence the lactation period.

In this situation the rule of $3 \sigma$ was used for the most differing breed groups (as illustrated in Figs. 3a, 3b, 3c). Irrespective of the breeding structure of the analyzed population, the upper limit value $(+3 \sigma)$ was greater than the critical value of 297 days accepted by SYMLEK (Table 3). 


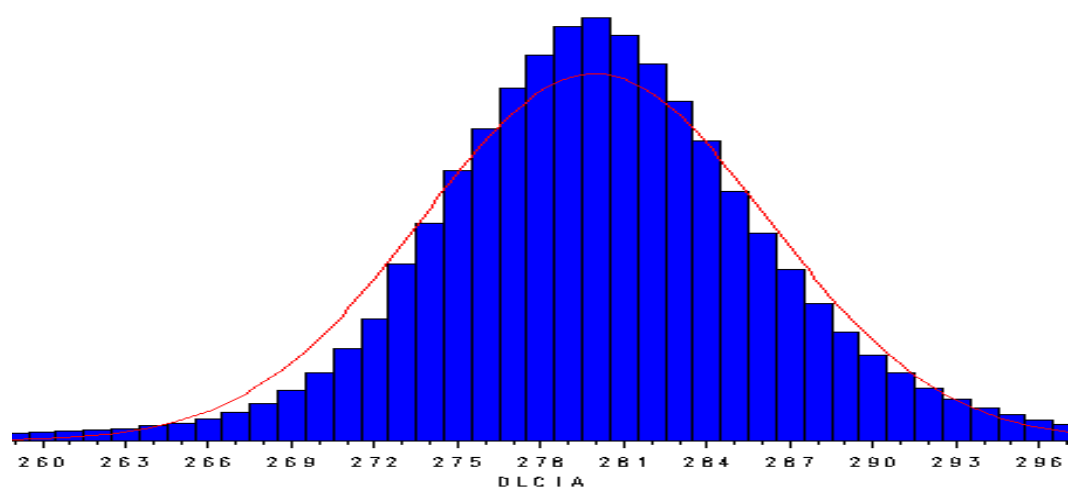

Figure 3a. Density function graph $\mathrm{f}(\mathrm{x})$ for empirical data - all 9 breeds

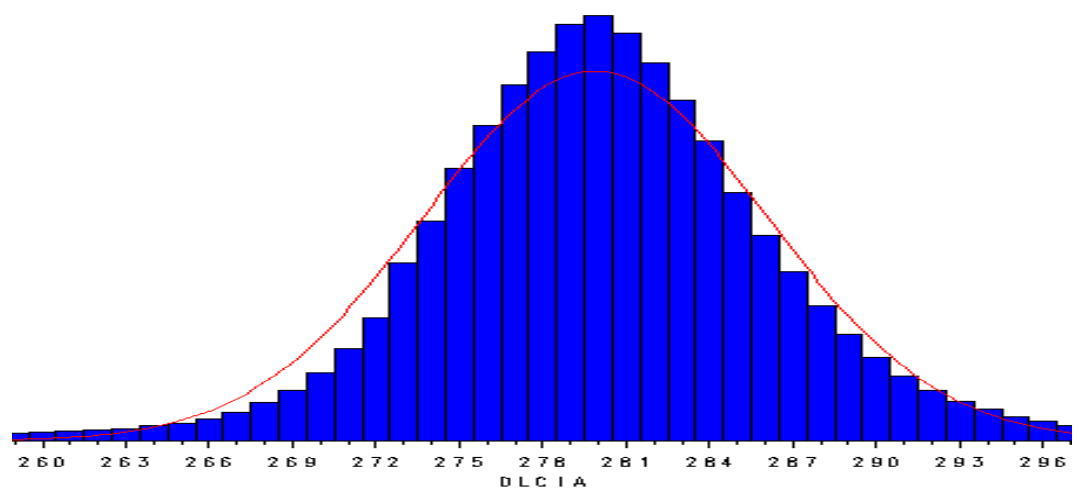

Figure 3b. Density function graph $\mathrm{f}(\mathrm{x})$ for empirical data - the whole set except Montbéliard and Simental

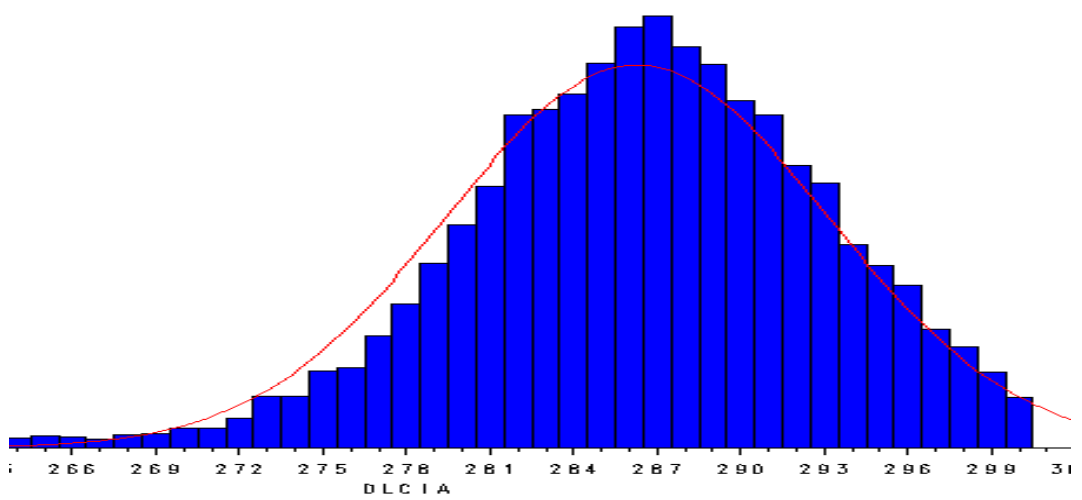

Figure 3c. Density function graph $f(x)$ for empirical data - the set of 2 breeds: Montbéliard and Simental 
Table 3. Mean gestation length in different dairy cattle breeds

\begin{tabular}{llllllll}
\hline Groups & $-3 \sigma$ & $-2 \sigma$ & $-1 \sigma$ & mean & $+1 \sigma$ & $+2 \sigma$ & $+3 \sigma$ \\
\hline All 9 breeds & 261.29 & 267.51 & 273.73 & 279.95 & 286.18 & 292.40 & 298.62 \\
Excluding SM and MO & 261.35 & 267.53 & 273.71 & 279.88 & 286.07 & 292.24 & 298.42 \\
Only SM +MO & 279.46 & 279.46 & 279.46 & 286.28 & 293.10 & 299.91 & 306.73 \\
\hline
\end{tabular}

Because of the highly significant difference between the mean for the Montbéliard and Simental group and that for the remaining dairy cattle groups, it is advisable to adopt different acceptable extreme values. For the group of Montbéliard and Simental the critical value should be no shorter than 306 days, while for the remaining dairy cattle breeds it should be no shorter than 298 days.

The concordance of gestation length with a normal distribution proves that this trait had not undergone direct selection. According to Hansen et al. (2004) the heritability value for gestation length is 0.42 , while according to Jamrozik et al. (2005) it is 0.31 . This suggests the genetic possibility of changing this trait. However, selection for changing gestation length is undesirable, as extreme values of this trait may lead to calving difficulties and stillbirths (Olson et al., 2009).

\section{Conclusions}

The studies, conducted on a very large dairy cow population, indicate that the gestation length trait follows a normal distribution. A significant difference was found between Montbéliard and Simental and the remaining breeds, so two extreme values for gestation length are proposed: 306 days for Montbéliard and Simental, and 298 days for the remaining breeds. Adoption of this change to the assessment instructions would enable a reduction in the costs of parentage control for calves born following a gestation longer than 297 days, which might undoubtedly reduce breeders' costs. 


\section{REFERENCES}

Feller W. (1971): An Introduction to Probability and its Applications. Wiley, New York.

Hansen M., Lund M.S., Pedersen J., Christensen L.G. (2004): Gestation length in Danish Holsteins has weak genetic associations with stillbirth, calving difficulty, and calf size. Livestock Production Science 91: 23-33.

Jamrozik J., Fatehi J., Kistemaker G.J., Schaeffer L.R. (2005): Estimates of genetic parameters for Canadian Holstein female reproduction traits. J. Dairy Sci. 88: 2199-2208.

Lopez de Maturana E., Wu X.-L., Gianola D., Weigel K.A., Rosa G.J.M. (2009): Exploring Biological Relationships Between Calving Traits in Primiparous Cattle with a Bayesian Recursive Model. Genetics 181: 277-287.

Norman H.D., Wright M.T., Kuhn S.M., Hubbard J.B., Cole J.B., VanRaden P.M. (2009): Genetic and environmental factors that affect gestation length in dairy cattle. J. Dairy Sci. 92: 2259-2269.

Olson K.M., Cassel B.G., McAllister A.J., Washburn S.P. (2009): Dystocia, stillbirth, gestation length, and birth weight in Holstein, Jersey, and reciprocal crosses from a planned experiment. J. Dairy Sci. 92: 6167-6175.

Petrović M.D., Bogdanowić V., Bogosavljević-Boškowić S., Dokovoć R. (2010): Effect of Systematic Factors on Gestation Length in Simmental Cows. Acta Agriculturae Serbica XV(29): 31-37.

SAS (2010): SAS/STAT User's Guide. Cary, NC: SAS Institute Inc.

Xing Ch., Li Y., Zhang K., Wang L. (2011): Shadow detecting using particle swarm optimization and the Kolmogorov test. Computers and Mathematics with Applications 62: 2704-2711. 